Case Report

\title{
N-Acetyl-Cysteine as Effective and Safe Chelating Agent in Metal-on-Metal Hip-Implanted Patients: Two Cases
}

\author{
Andrea Giampreti, ${ }^{1}$ Davide Lonati, ${ }^{1}$ Benedetta Ragghianti, ${ }^{2}$ Anna Ronchi, ${ }^{1}$ \\ Valeria Margherita Petrolini, ${ }^{1}$ Sarah Vecchio, ${ }^{1}$ and Carlo Alessandro Locatelli ${ }^{1}$ \\ ${ }^{1}$ Pavia Poison Centre and National Toxicology Information Centre, IRCCS Maugeri Foundation Clinical Institute and \\ University of Pavia, 27100 Pavia, Italy \\ ${ }^{2}$ Diabetes Agency, Careggi Teaching Hospital, 50134 Firenze, Italy
}

Correspondence should be addressed to Andrea Giampreti; andrea.giampreti@unipv.it

Received 15 December 2015; Accepted 20 March 2016

Academic Editor: Eyal Itshayek

Copyright (c) 2016 Andrea Giampreti et al. This is an open access article distributed under the Creative Commons Attribution License, which permits unrestricted use, distribution, and reproduction in any medium, provided the original work is properly cited.

Systemic toxicity associated with cobalt $(\mathrm{Co})$ and chromium $(\mathrm{Cr})$ containing metal hip alloy may result in neuropathy, cardiomyopathy, and hypothyroidism. However clinical management concerning chelating therapy is still debated in literature. Here are described two metal-on-metal hip-implanted patients in which $\mathrm{N}$-acetyl-cysteine decreased elevated blood metal levels. A 67-year-old male who underwent Co/Cr hip implant in September 2009 referred to our Poison Control Centre for persisting elevated Co/Cr blood levels (from March 2012 to November 2014). After receiving oral high-dose $\mathrm{N}$-acetyl-cysteine, Co/Cr blood concentrations dropped by $86 \%$ and $87 \%$ of the prechelation levels, respectively, and persisted at these latter concentrations during the following 6 months of follow-up. An 81-year-old female who underwent Co/Cr hip implant in January 2007 referred to our Centre for detection of high Co and Cr blood levels in June 2012. No hip revision was indicated. After a therapy with oral highdose $\mathrm{N}$-acetyl-cysteine $\mathrm{Co} / \mathrm{Cr}$ blood concentrations decreased of $45 \%$ and $24 \%$ of the prechelation levels. Chelating agents reported in hip-implanted patients (EDTA, DMPS, and BAL) are described in few cases. $\mathrm{N}$-acetyl-cysteine may provide chelating sites for metals and in our cases reduced Co and Cr blood levels and resulted well tolerable.

\section{Introduction}

Safety concerns regarding wear and corrosion of cobalt/ chromium $(\mathrm{Co} / \mathrm{Cr})$ containing hip prosthetics and subsequent $\mathrm{Co} / \mathrm{Cr}$ release have resulted in products recall, public alert, and need for clinicians, health authorities, and scientific societies to evaluate and follow up metal-on-metal (MOM) hip-implanted patients for local and systemic toxic effects [1] However only few reports of systemic toxicity from metals released from hip implant have been described in the literature [2]. Moreover consensus statement and evidence based data on management for MOM hip arthroplasty are mainly focused on hip implant-related problems as implant failure, local metallosis, and hip pain; nowadays minor attention is focused on toxicological management [3-5]. Regulatory agencies that tried to rule the management and follow-up of patients with metal hip implant focused mainly on orthopedic evaluation, imaging monitoring (e.g., Magnetic Resonance Imaging in Metal Artifact Reduction (MARS) techniques, CT scan, and hip echography), and metal blood tests. Toxicologic evaluation and decision concerning possible specific therapy, when chelating therapy should be evaluated, or which chelating agent should be chosen are often less treated and more debated topics [6]. In particular no data and no clinical experience exist concerning chelating therapy in asymptomatic MOM hip-implanted patients in which blood cobalt levels are elevated. We describe two MOM hipimplanted patients in which mildly elevated blood cobalt levels were associated with absence of systemic manifestations of cobaltism and chelating therapy with $\mathrm{N}$-acetyl-cysteine (NAC) resulted effective and safe in decreasing $\mathrm{Co} / \mathrm{Cr}$ blood levels. 


\section{Case Reports}

Case 1. In May 2012, a 67-year-old male patient was referred to our Poison Control Centre for detection of high Co $(16.06 \mathrm{mcg} / \mathrm{L}$; normal value $<0.9)$ and $\mathrm{Cr}(7.22 \mathrm{mcg} / \mathrm{L}$; normal value < 0.5) blood levels in March 2012 (Figure 1(a)). His past medical history was positive only for previous cochlear implant in 2005 and hypertension in treatment with candesartan cilexetil and hydrochlorothiazide. In September 2009, the patient underwent MOM Co/Cr alloy total hip implantation for left coxarthrosis (DePuy ASR ${ }^{\mathrm{TM}}$ XL Hip System). The postoperative clinical course was good with normal range of movement and no local pain. Except for $\mathrm{Co} / \mathrm{Cr}$ blood levels, laboratory exams (blood chemistry and thyroid function) and instrumental evaluation (echocardiography and electromyography/electroneurography at superior and inferior limbs) resulted normal. An orthopedic evaluation evidenced no signs or symptoms of implant failure and an echography performed on March 2012 resulted negative for local reactions or massive fluid collection near the implant. Magnetic Resonance Imaging in MARS techniques performed in November 2012 evidenced a little fluid collection near the acetabular cup that progressively reduced at the control in March 2013 and April and December 2014. Considering the presence of elevated $\mathrm{Co} / \mathrm{Cr}$ blood levels in absence of other local and systemic manifestations the patient underwent metal monitoring on blood samples for the following three years (Figure 1(a)). Due to the persisting elevated $\mathrm{Co} / \mathrm{Cr}$ blood levels (Co above $20 \mathrm{mcg} / \mathrm{L}$ and $\mathrm{Cr}$ above $7 \mathrm{mcg} / \mathrm{L}$ ) a chelation therapy with oral high-dose NAC $(300 \mathrm{mg} / \mathrm{kg} /$ day for 10 days) was performed in November 2014. NAC was well tolerated and no adverse reactions were reported. $\mathrm{Co} / \mathrm{Cr}$ blood concentrations performed in December 2014 immediately after the chelation dropped by about $86 \%$ and $87 \%$ of the prechelation levels, respectively, and persisted at these latter concentrations during the following 6 months (Figure 1(a)). Also urine $\mathrm{Co} / \mathrm{Cr}$ concentrations modified during $\mathrm{NAC}$ administration and increased by about 4- and 3-fold, respectively (Co urine levels increased from 6 to $23 \mathrm{mcg} / \mathrm{L}$; Cr urine levels increased from 2 to $6 \mathrm{mcg} / \mathrm{L}$ ). At a 3 -year follow-up, the patient remained asymptomatic, with no signs of local or systemic effects and persisting low $\mathrm{Co} / \mathrm{Cr}$ blood levels.

Case 2. In November 2013, an 81-year-old female patient was referred to our Poison Control Centre for detection of high Co $(20.24 \mathrm{mcg} / \mathrm{L})$ and $\mathrm{Cr}(4.25 \mathrm{mcg} / \mathrm{L})$ blood levels in June 2012 (Figure 1(b)). Her past medical history was positive for COPD, systemic lupus erythematosus, moderate mitral and aortic valve regurgitation, and mild renal impairment (CKD-epi calculated creatinine clearance $52 \mathrm{~mL} / \mathrm{min}$ ). Euthyroid multinodular goiter, hypertension, and bilateral cataracts were also reported before implant date. In January 2007 the patient underwent MOM total left hip arthroplasty (DePuy ASR ${ }^{\mathrm{m}}$ Hip System) for traumatic fracture. Clinical course from 2008 to 2013 was characterized by local hip pain due to postoperative myositis ossificans associated with periprosthetic fluid collection evidenced at CT imaging and hip scintigraphy. No systemic signs or symptoms of cobaltism such as peripheral polyneuropathy, hypothyroidism, or pericardial exudate were evidenced and considering particular risk factors (extreme age and patient's comorbidities) no hip revision was indicated. Due to the persisting elevated Co/Cr blood levels (Co above $20 \mathrm{mcg} / \mathrm{L}$ and $\mathrm{Cr}$ above $8 \mathrm{mcg} / \mathrm{L}$ ) a chelation therapy with oral highdose NAC (300 mg/kg/day for 9 days) was performed in April 2014 (Figure 1(b)). Co/Cr blood concentrations performed during chelation therapy revealed a decrease of $\mathrm{Co} / \mathrm{Cr}$ blood concentrations of $45 \%$ and $24 \%$ of the prechelation levels, respectively, and an increase in $\mathrm{Co} / \mathrm{Cr}$ urine excretion (Co from 21.9 to $39.5 \mathrm{mcg} / \mathrm{L}$; Cr from 6 to $15.6 \mathrm{mcg} / \mathrm{L}$ ). No adverse reactions have been evidenced during therapy except for a slight increase in body weight and blood pressure promptly reversed with diuretic treatment (oral furosemide $20 \mathrm{mg}$ ). At a recent follow-up, the patient is stable, with no signs of local or systemic $\mathrm{Co} / \mathrm{Cr}$ effects. The metal monitoring revealed a progressive increase of $\mathrm{Co}$ and $\mathrm{Cr}$ blood concentrations during the following 8 months after the chelation therapy (Figure 1(b)).

\section{Discussion}

In recent years, safety concerns regarding MOM hip prosthesis have been raised [1]. Local and systemic toxicity associated with $\mathrm{Co} / \mathrm{Cr}$ containing metal hip alloy have been reported and mainly related to Co. Arthroprosthetic cobaltism may result in neuropathy, cardiomyopathy, and hypothyroidism with late onset from prosthesis implantation. However toxicological evaluation and clinical management concerning hip surgical revision and particularly chelating therapy are still debated [12]. The role of different chelating agents, timing of administration, and chelating efficacy seem to represent debated aspects in $\mathrm{Co} / \mathrm{Cr}$ chelation and in clinical management of MOM hip-implanted patients [2, 13].

Concerning the type of prostheses it has been considered that head size and implant design may play an important role in the risk of implant wear and metal ions release. For total hip implant, small heads implant presents a little additional risk of adverse reaction to metal debris and bearings surface wear. On the other hand large head implant $(36 \mathrm{~mm}$ head size and larger) may present a higher risk of taper wear, rim loading, and reduced bearing lubrication (particularly if associated with high abduction angle) with consequent increased risk for local adverse reaction to metal debris and systemic release of metal ions and particles [4].

Concerning systemic manifestations nowadays only few reports concerning arthroprosthetic cobaltism have been published in medical literature. Despite the fact that a clear and shared toxic threshold for systemic cobaltism is not reported, clinical manifestations as cardiotoxicity, peripheral neuropathy, and thyroid toxicity have been associated with high blood cobalt levels above 100, 250, and $500 \mathrm{mcg} / \mathrm{L}$, respectively; on the other hand sensorineural hearing loss and ocular toxicity have been anecdotally associated with lower Co blood levels above 20 and $40 \mathrm{mcg} / \mathrm{L}$, respectively $[2,14,15]$. In our cases, despite cobalt blood levels being above $20 \mathrm{mcg} / \mathrm{L}$ in both patients, no signs of ocular disease or sensorineural 


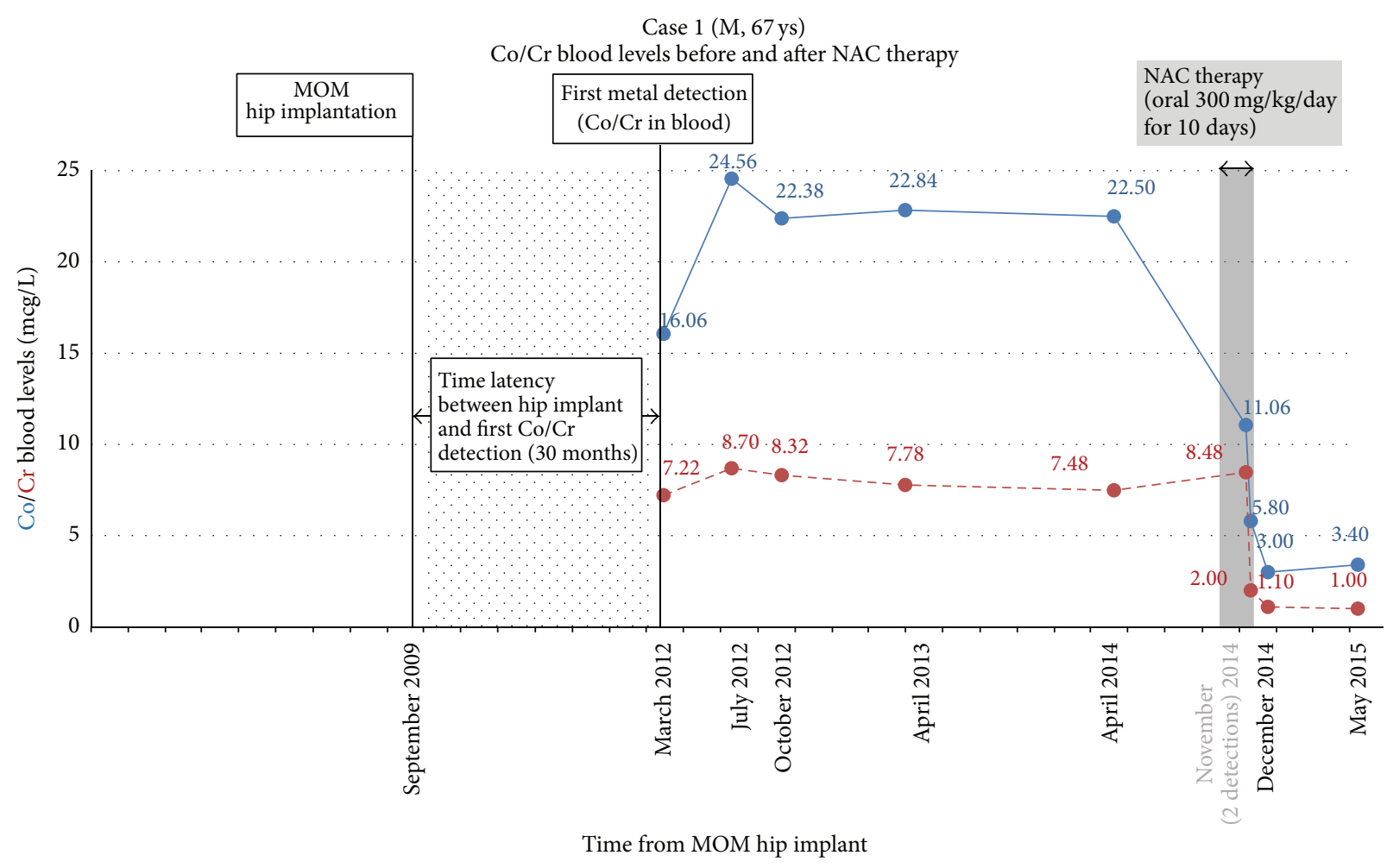

(a)

Case 2 (F, 81 ys)

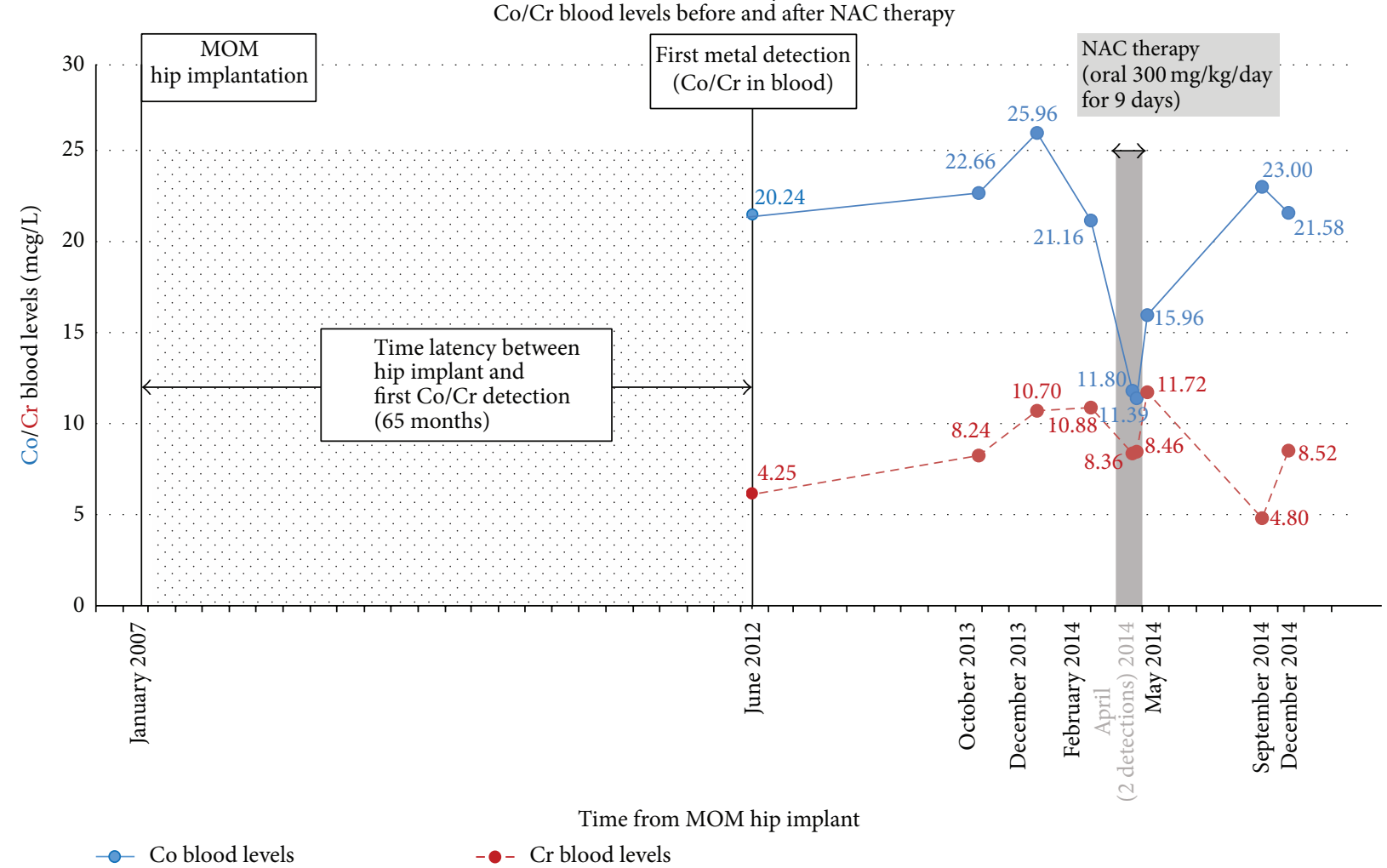

(b)

Figure 1: (a) Cobalt (Co) and chromium (Cr) blood levels in case 1. In the figure are reported time latency from MOM implant and first metal detection and metal blood concentrations before, during, and after chelation treatment with high-dose oral NAC. (b) Cobalt (Co) and chromium ( $\mathrm{Cr}$ ) blood levels in case 2. In the figure are reported time latency from MOM implant and first metal detection and metal blood concentrations before, during, and after chelation treatment with high-dose oral NAC. 


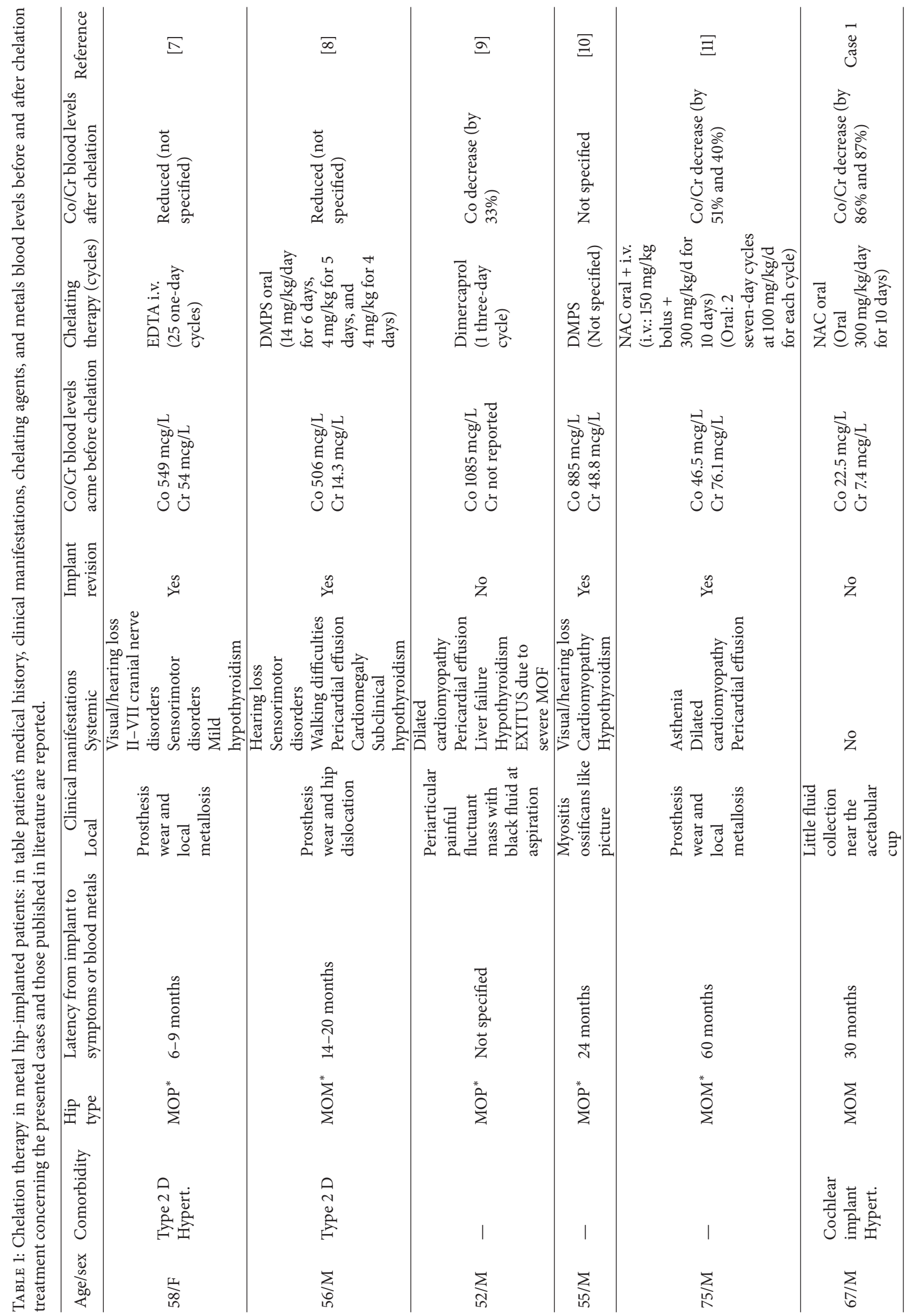




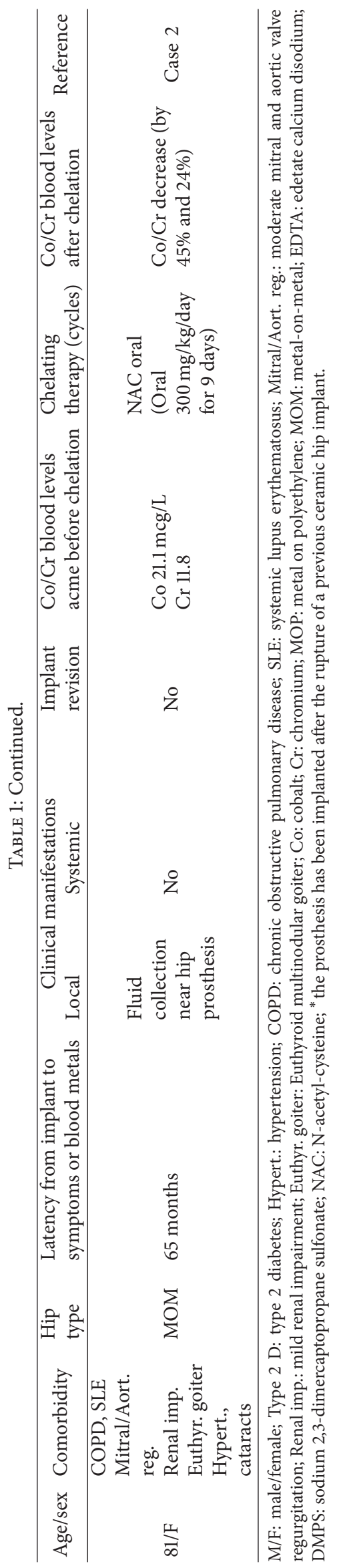


hearing worsening have been evidenced from hip implantation and a clinical management based on metal monitoring and seriated hear and visual control has been decided. Cochlear implant in case 1 and goiter and bilateral cataracts in case 2 were presented before hip implantation and no signs of clinical worsening have been detected after hip implant.

Concerning chelation therapy, $\mathrm{Co}$ and $\mathrm{Cr}$ chelation in MOM hip-implanted patients has been described in few cases. Chelating agents such as edetate calcium disodium (EDTA), sodium 2,3-dimercaptopropane sulfonate (DMPS), and dimercaprol (BAL) have been reported (Table 1) [7-10].

EDTA is used to bind metal ions in the practice of chelation therapy mainly for mercury and lead poisoning. It binds to a metal cation through its two amines and four carboxylates sites, enhancing metal elimination through renal excretion. Dimercaprol and DMPS are chelating agents principally involved in the treatment of poisoning by arsenic and polonium-210, respectively. Both are characterized by the presence in the molecular structure of two thiol groups that bind metal ions consequently excreted in the urine. Animal data have suggested that chelating sites of EDTA and thiol groups of dimercaprol and DMPS could be effective in chelating cobalt [16]. However anecdotal use in MOM hipimplanted patient has been described for EDTA (1 case), dimercaprol (1 case), and DMPS (2 cases). At present their efficacy and place in therapy for arthroprosthetic cobaltism remain anecdotal. It has also been kept in mind that potential renal, hepatic, or gastrointestinal adverse effects may result from EDTA, DMPS, and BAL administration, respectively [17-19]. Moreover all hip-implanted patients in which these agents have been administered removed the metal source of exposure; in fact they underwent hip implant revision because they presented severe clinical manifestations of systemic cobaltism and significantly elevated cobalt blood levels (Table 1).

Our cases presented $\mathrm{Co} / \mathrm{Cr}$ blood levels lower than reported for patients that underwent hip revision and chelation therapy. Moreover, except for mild fluid collection near the prosthesis, no local or systemic manifestations of cobaltism have been registered. In current medical literature different published consensus statement on metal-on-metal total hip replacement and hip resurfacing establish that in asymptomatic patients with well-functioning hip implant but elevated Co levels the individual risk-benefit-ratio should be carefully considered for hip revision and no indications concerning which, how, and when a chelating approach should be evaluated are presented $[3,4]$. In our cases slightly elevated blood cobalt levels, optimal clinical condition in case 1, and patient's comorbidities in case 2 seemed to be reasonable conditions to wait for hip implant revision. Due to the persisting increased $\mathrm{Co} / \mathrm{Cr}$ blood levels a chelating approach has been evaluated. Clinical experience is very limited and chelation in these patients needs to be carefully evaluated. Thiol groups in N-acetyl-cysteine (NAC) may provide chelating sites for metals. Animal studies on comparative effects of repeated administration of different chelators on the distribution and excretion of Co evidenced that NAC both increases urine elimination and decreases tissues concentration of Co [16, 20]. Moreover also recent in vitro data evidence that NAC may chelate and form conjugates with cobalt [21]. NAC has been reported not only as effective and safe Co chelating agent in some animal models but also as potential Co chelator in one previously recently reported human case of severe arthroprosthetic cobaltism [11, 16, 20]. In our cases, NAC was preferred to other agents due to its potential safer profile and possible oral administration. High-dose NAC was orally administered and reduced $\mathrm{Co}$ and $\mathrm{Cr}$ blood levels under or near MHRA Co attention level of $7 \mathrm{mcg} / \mathrm{L}$ [6]. Moreover in both case 1 and case 2 an increase in urine $\mathrm{Co}$ and $\mathrm{Cr}$ levels was observed during NAC administration. In case 1 metal levels persisted to be low up to 6 months after NAC administration while in case $2 \mathrm{Co} / \mathrm{Cr}$ levels presented an increase during the following 8 months from NAC. This may be explained by a mild renal impairment associated with a longer exposure and subsequent larger accumulation of cobalt in case 2 (about 65 months) than in case 1 (about 30 months) that may induce a greater metal redistribution from deep tissues into blood. Moreover recent toxicokinetic studies hypothesized that women (as case 2) generally absorb more and excrete less Co than men (as case 1) [22, 23].

Clinical management of patients with MOM hip prosthesis is complex and is currently characterized by several debated aspects concerning surgical and toxicological management and follow-up. In patients with MOM hip implant and persisting increased $\mathrm{Co} / \mathrm{Cr}$ blood levels a continuous exposure to $\mathrm{Co}$ and $\mathrm{Cr}$ cannot be excluded and a chelating approach may be considered. Also, if only in two cases, in our experience oral high-dose NAC resulted well tolerable and reduced elevated $\mathrm{Co} / \mathrm{Cr}$ blood levels of MOM hip-implanted asymptomatic patients.

\section{Disclosure}

An abstract (about case 2) has been accepted for the XXXIV International Congress of the European Association of Poisons Centres and Clinical Toxicologists (EAPCCT) 27-30 May 2014, Brussels, Belgium. The authors alone are responsible for the content and writing of the paper.

\section{Competing Interests}

The authors report no competing interests.

\section{References}

[1] J. J. Devlin, A. C. Pomerleau, J. Brent, B. W. Morgan, S. Deitchman, and M. Schwartz, "Clinical Features, Testing, and Management of Patients with Suspected Prosthetic Hip-Associated Cobalt Toxicity: A Systematic Review of Cases," Journal of Medical Toxicology, vol. 9, no. 4, pp. 405-415, 2013.

[2] S. M. Bradberry, J. M. Wilkinson, and R. E. Ferner, "Systemic toxicity related to metal hip prostheses," Clinical Toxicology, vol. 52, no. 8, pp. 837-847, 2014.

[3] F. Hannemann, A. Hartmann, J. Schmitt et al., "European multidisciplinary consensus statement on the use and monitoring of metal-on-metal bearings for total hip replacement and hip resurfacing," Orthopaedics and Traumatology: Surgery and Research, vol. 99, no. 3, pp. 263-271, 2013. 
[4] K. P. Günther, J. Schmitt, P. Campbell et al., "Consensus statement 'Current evidence on the management of metal-onmetal bearings"' Hip International, vol. 23, no. 1, pp. 2-5, 2013.

[5] Y.-M. Kwon, J. J. Jacobs, S. J. MacDonald, H. G. Potter, T. K. Fehring, and A. V. Lombardi, "Evidence-based understanding of management perils for metal-on-metal hip arthroplasty patients," The Journal of Arthroplasty, vol. 27, no. 8, supplement, pp. 20-25, 2012.

[6] MDA/2012/036, Medical Device Alert: All metal-on-metal (MoM) hip replacements, Issued 25, Medicines and Healthcare products Regulatory Agency (MHRA), June 2012.

[7] U. E. Pazzaglia, P. Apostoli, T. Congiu, S. Catalani, M. Marchese, and G. Zarattini, "Cobalt, chromium and molybdenum ions kinetics in the human body: data gained from a total hip replacement with massive third body wear of the head and neuropathy by cobalt intoxication," Archives of Orthopaedic and Trauma Surgery, vol. 131, no. 9, pp. 1299-1308, 2011.

[8] D. Pelclova, M. Sklensky, P. Janicek, and K. Lach, "Severe cobalt intoxication following hip replacement revision: clinical features and outcome," Clinical Toxicology, vol. 50, no. 4, pp. 262$265,2012$.

[9] C. J. Gilbert, A. Cheung, J. Butany et al., "Hip pain and heart failure: the missing link," Canadian Journal of Cardiology, vol. 29, no. 5, pp. 639.el-639.e2, 2013.

[10] K. Dahms, Y. Sharkova, P. Heitland, S. Pankuweit, and J. R. Schaefer, "Cobalt intoxication diagnosed with the help of Dr House," The Lancet, vol. 383, no. 9916, p. 574, 2014.

[11] A. Giampreti, D. Lonati, and C. A. Locatelli, "Chelation in suspected prosthetic hip-associated cobalt toxicity," Canadian Journal of Cardiology, vol. 30, no. 4, p. 465.e13, 2014.

[12] J. Brent and J. J. Devlin, "Dilemmas about the toxicological consequences of metal-on-metal hip prostheses. What we do and do not know, and what we should do?" Clinical Toxicology, vol. 51, no. 4, pp. 195-198, 2013.

[13] J. J. Devlin, M. Schwartz, and J. Brent, "Chelation in suspected prosthetic hip-associated cobalt toxicity," Canadian Journal of Cardiology, vol. 29, no. 11, p. 1533.e7, 2013.

[14] S. Tower, "Arthroprosthetic cobaltism: identification of the atrisk patient," Alaska Medicine, vol. 52, pp. 28-32, 2010.

[15] S. K. Ng, A. Ebneter, and J. S. Gilhotra, "Hip-implant related chorio-retinal cobalt toxicity," Indian Journal of Ophthalmology, vol. 61, no. 1, pp. 35-37, 2013.

[16] J. M. Llobet, J. L. Domingo, and J. Corbella, "Comparative effects of repeated parenteral administration of several chelators on the distribution and excretion of cobalt," Research Communications in Chemical Pathology and Pharmacology, vol. 60, no. 2, pp. 225233, 1988 .

[17] D. I. Moel and K. Kumar, "Reversible nephrotoxic reactions to a combined 2,3-dimercapto-1-propanol and calcium disodium ethylenediaminetetraacetic acid regimen in asymptomatic children with elevated blood lead levels," Pediatrics, vol. 70, no. 2, pp. 259-262, 1982.

[18] D. Gonzalez-Ramirez, M. Zuniga-Charles, A. Narro-Juarez et al., "DMPS (2,3-dimercaptopropane-1-sulfonate, dimaval) decreases the body burden of mercury in humans exposed to mercurous chloride," Journal of Pharmacology and Experimental Therapeutics, vol. 287, no. 1, pp. 8-12, 1998.

[19] M. B. Sulzberger, R. L. Baer, and A. Kanof, "Clinical uses of 2,3dimercaptopropanol (BAL). III. Studies on the toxicity of BAL on percutaneous and parenteral administration," The Journal of Clinical Investigation, vol. 25, no. 4, pp. 474-479, 1946.
[20] J. L. Domingo, J. M. Llobet, and J. M. Tomás, "N-acetyl-Lcysteine in acute cobalt poisoning.," Archivos de Farmacologia y Toxicologia, vol. 11, no. 1, pp. 55-62, 1985.

[21] M. W. Luczak and A. Zhitkovich, "Role of direct reactivity with metals in chemoprotection by $\mathrm{N}$-acetylcysteine against chromium(VI), cadmium(II), and cobalt(II)," Free Radical Biology and Medicine, vol. 65, pp. 262-269, 2013.

[22] K. M. Unice, B. D. Kerger, D. J. Paustenbach, B. L. Finley, and B. E. Tvermoes, "Refined biokinetic model for humans exposed to cobalt dietary supplements and other sources of systemic cobalt exposure," Chemico-Biological Interactions, vol. 216, no. 1, pp. 53-74, 2014.

[23] B. E. Tvermoes, D. J. Paustenbach, B. D. Kerger, B. L. Finley, and K. M. Unice, "Review of cobalt toxicokinetics following oral dosing: implications for health risk assessments and metal-onmetal hip implant patients," Critical Reviews in Toxicology, vol. 45, no. 5, pp. 367-387, 2015. 


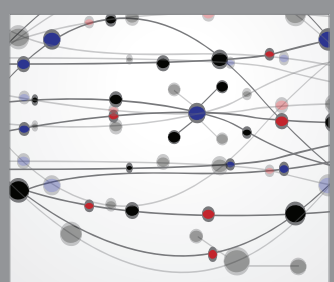

The Scientific World Journal
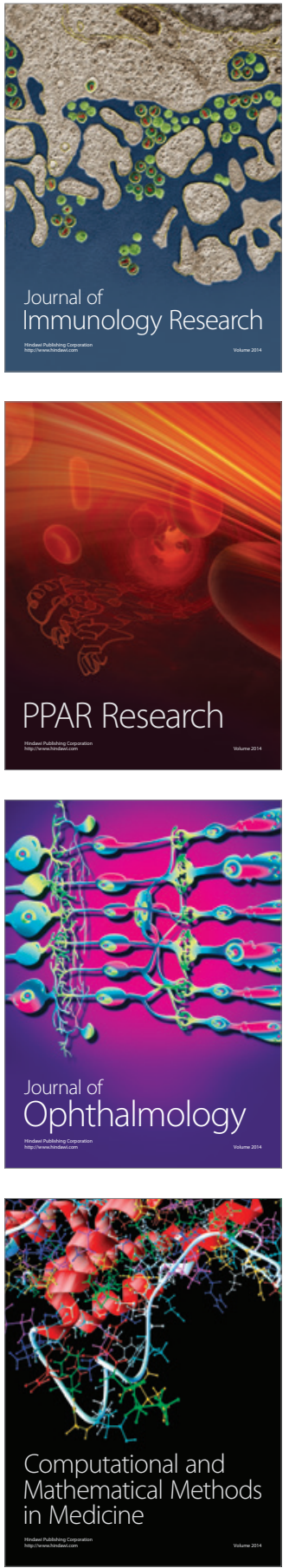

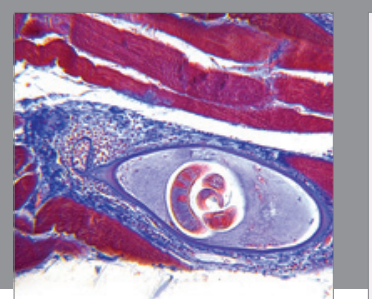

Gastroenterology Research and Practice

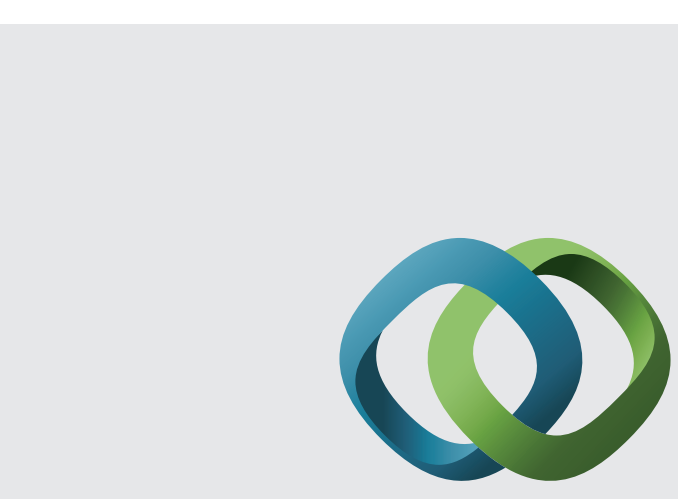

\section{Hindawi}

Submit your manuscripts at

http://www.hindawi.com
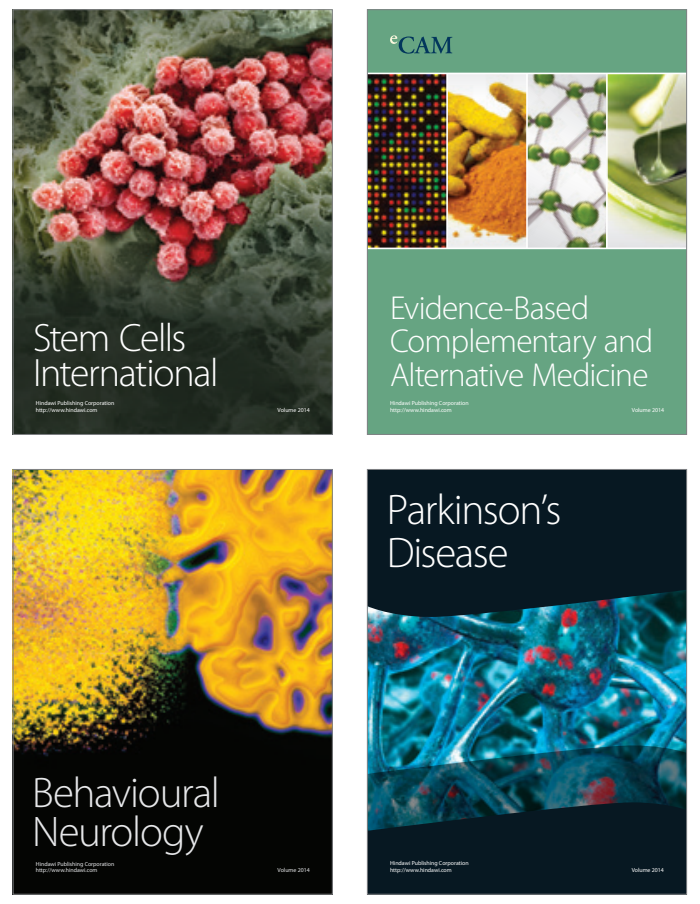
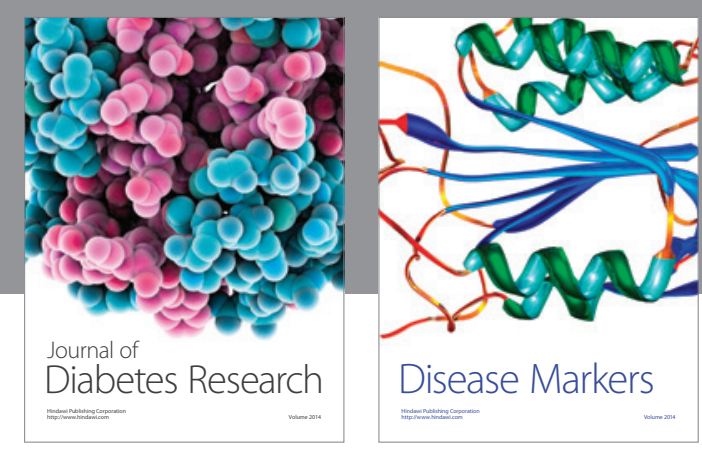

Disease Markers
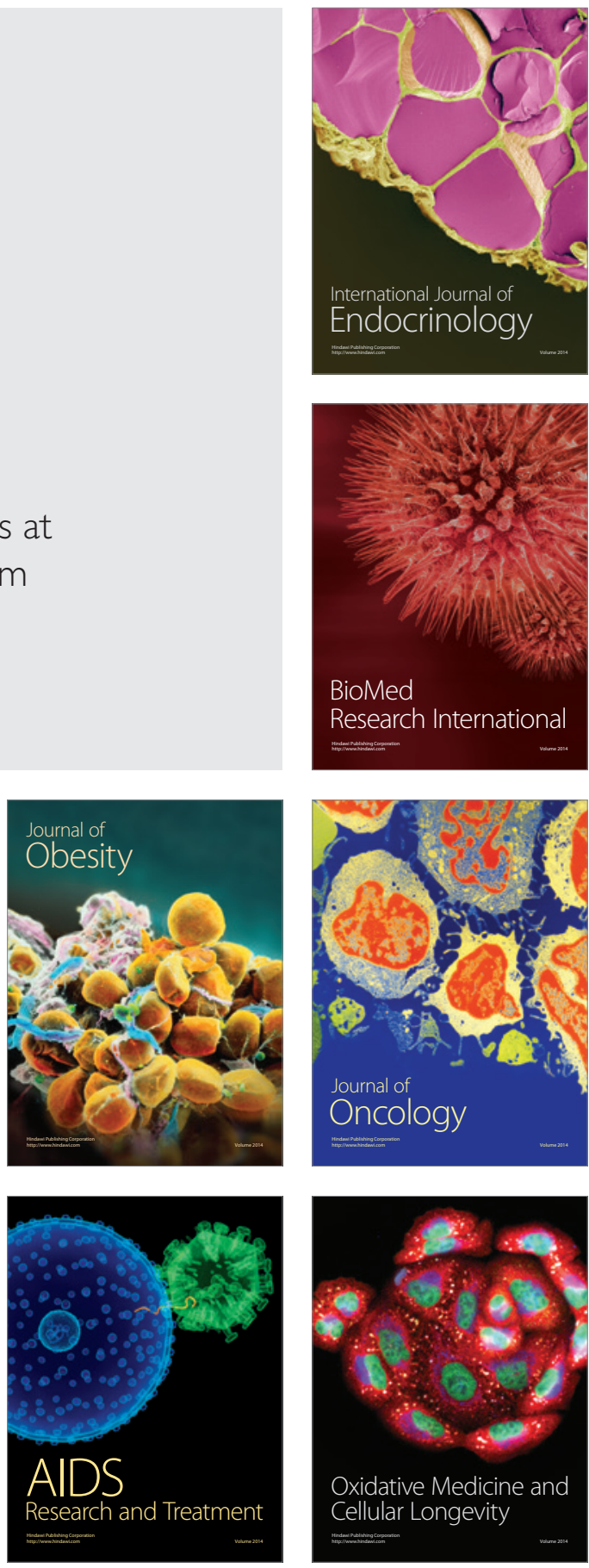